\title{
WHAT I KNOW ABOUT LATE IMPROVEMENTS OF THE MICROSCOPE.
}

[Read before the Biological and Microscopical Section of the Academy of Natural Sciences, Philadelphia, June 4th, 1877.]

By Joseph Zentmayer.

A recent paper, by our fellow-member, Dr. J. G. Hunt, entitled: "Post-Centennial Microscopical Notes," read before this section, and published in the Cincinnati Medical News, has provoked considerable discussion, especially that part relating to my "American Centennial Microscope." As some of these important improvements have been claimed by other makers, I propose to bring the subject before you for investigation, with the endeavor to right the matter satisfactorily to all concerned.

In order to make the investigation a thorough one, it will be necessary for me to call your attention to the so-called Grand American Stand, made for this academy in October, 1859, and which now stands before you. The novel points of this stand, which I claimed at that time, were: 1st. The stage, with graduated revolving plate to serve as goniometer. Although very firm, it is only $\frac{3}{16}{ }^{\prime \prime}$ thick, and is, even at the present date, the thinnest mechanical stage made. $2 \mathrm{~d}$. The graduated revolving base for measuring the angular apertures of objectives. 3d. The hanging of the mirror to a joint as near as possible to the plane of the stage.

Early in 1860, I made three stands (Nos. 13, 14 and 15) precisely like the Grand American, but somewhat lighter. No. 15 was made for a gentleman who was not in favor of mechanical stages, and who desired me to design for him a revolving stagc, the object to be moved by hand, and it was for him that I construeted the first of my graduated stages, giving a complete revolution in the optical axis, in a large ring, which is adjustable within another by three screws, in order to have the axis of the stage coincident with the optical axis of the instrument, exactly the same as the one before you, which I made early in 1866. This stage has been for years extensively copied, in France and in England.

The hanging of the mirror hy a joint as near as possible to the stage, I adopted long before I made the Grand American Stand. The first large stand I made has such a swinging mirror.

Whole No. Vor. CIV.-(Third SERres, Vol. lxxiv.) 
The microscope, to which I will now call your attention, is one which I made in 1864; the owner has kindly loaned it to me for this evening. The accompanying photograph was made in November, 1864. It is one of my army hospital stands, almost the same as made to-day, except that a sliding sub-stage is attached to the prismatic mirror bar, to receive the accessories. In the photograph you see an achromatic prism for oblique illumination (an apparatus which since then has also been brought out as new). Although handy as a mechanical contrivance, it is not of much importance; the mirror stem is only jointed near the stage, and has not the object under observation as its precise centre. If it had, it would be exactly the same as the swinging sub-stage and mirror of my new "Centennial Stand." About two years ago, in a conversation with Dr. J. G. Hunt, he pointed out the importance of having an arrangement for illuminating the object by an Achromatic Condenser in an oblique position. I explained to him how I would make a stand, in which this idea would be carried out in the most complete manner. The design and drawings were made soon after, but the instrument was not brought out, as I intended it for the Centennial Exhibition. Some of you have seen it before, and previous to bringing it to the exhibition, you recollect, it was shown at our meeting here, in $\Lambda$ pril, 1876.

Messrs. Bausch \& Lomb, of Rochester, N. Y., exhibited at the Centennial, a microscope stand with glass stage (a modification of mine); the mirror was hung to a swinging arm, and a diaphragm was attached to the mirror stem, quite similar to the instrument and photograph before you, made 13 years ago. The joint was not in a plane with the object, but below the surface of the stage, and the diaphragm was attached to a lateral slide, in order to make use of it when the mirror was hung obliquely, which is a clear proof that the joint was not in a plane with the object. I admit that in the way they accomplished it, they could have placed the joint higher, as they did in instruments brought into the Centennial Exhibition at a later time, but at a loss of extreme obliquity. To bring their mirror over the stage is utterly impossible.

A few days ago Dr. J. G. Hunt showed to me a letter received from Mr. W. H. Bulloch, of Chicago, accompanied by cuts and photographs. Dr. Hunt had the kindness to hand the photographs and cuts over to me, and I lay them before you. One photograph shows that Mr. Bulloch has adopted my circular, graduated, adjustable glass 
stage, claiming this old invention of mine as his own. According to his statement he made it first in July, 1870, just 10 years after I introduced it.

The large cut and the other photograph represent his large Binocular Stand, also with adjusting screws to the adjusting revolving stage. The mirror stem is apparently stationary, and the mirror is attached to it by a double joint, permitting of some oblique illumination. But the important part of this instrument is an arc below the stage, which is traversed by the sub-stage. The centre of the arc is evidently in the plane with the object, and therefore the sub-stage can be placed radial to the object, provided the somewhat complicated mechanism is made and used with care. The angle of obliquity, of course, is a limited one, and even with a stage as small and thin as my Diatom Stage, it would not be possible to obtain, either with mirror or condenser, an angle sufficiently great for the present requirements. As the mirror does not swing with the sub-stage, it is difficult to get the mirror centered with the condenser. The photograph is marked 1873, making it evident that it is the first attempt to place the achromatic condenser in an oblique position to the optical axis. But comparing this arrangement with mine, as designed and adapted to my stands, the difference in the results, although involving the same principle, will be seen at once. The design of Mr. Bulloch is a heavy, costly attachment, limited in its movement, and unhandy, as the mirror does not follow the sub-stage, and when the mirror is used alone it is of no use whatever. In mine the mirror and sub-stage movement is only limited by the body of the microscope, and can be used below or above the stage, always having the object at its centre, and in such a simple way that not a single extra piece is added to an instrument with the ordinary swinging mirror; hence we can adapt it to our cheapest microscopes. Mr. Bulloch claims to be the first to use the mirror above the stage instead of the bull's-eye. According to his own statement, in 1870, I can only say, if Mr. Bulloch did not accomplish it before that time, that he is the last one I know of, who invented it. Spencer, Tolles, others and myself did the same thing many years before; and the little so-called Candlestick Stand, made and presented to our section by. Mr. Ed. Tilghman, about 18 years ago, is capable of doing the same thing. Some accomplish it by detaching, others by adding, joints to the mirror. If accomplished in this way it is not worth the sacrifice of stability which is incurred. 


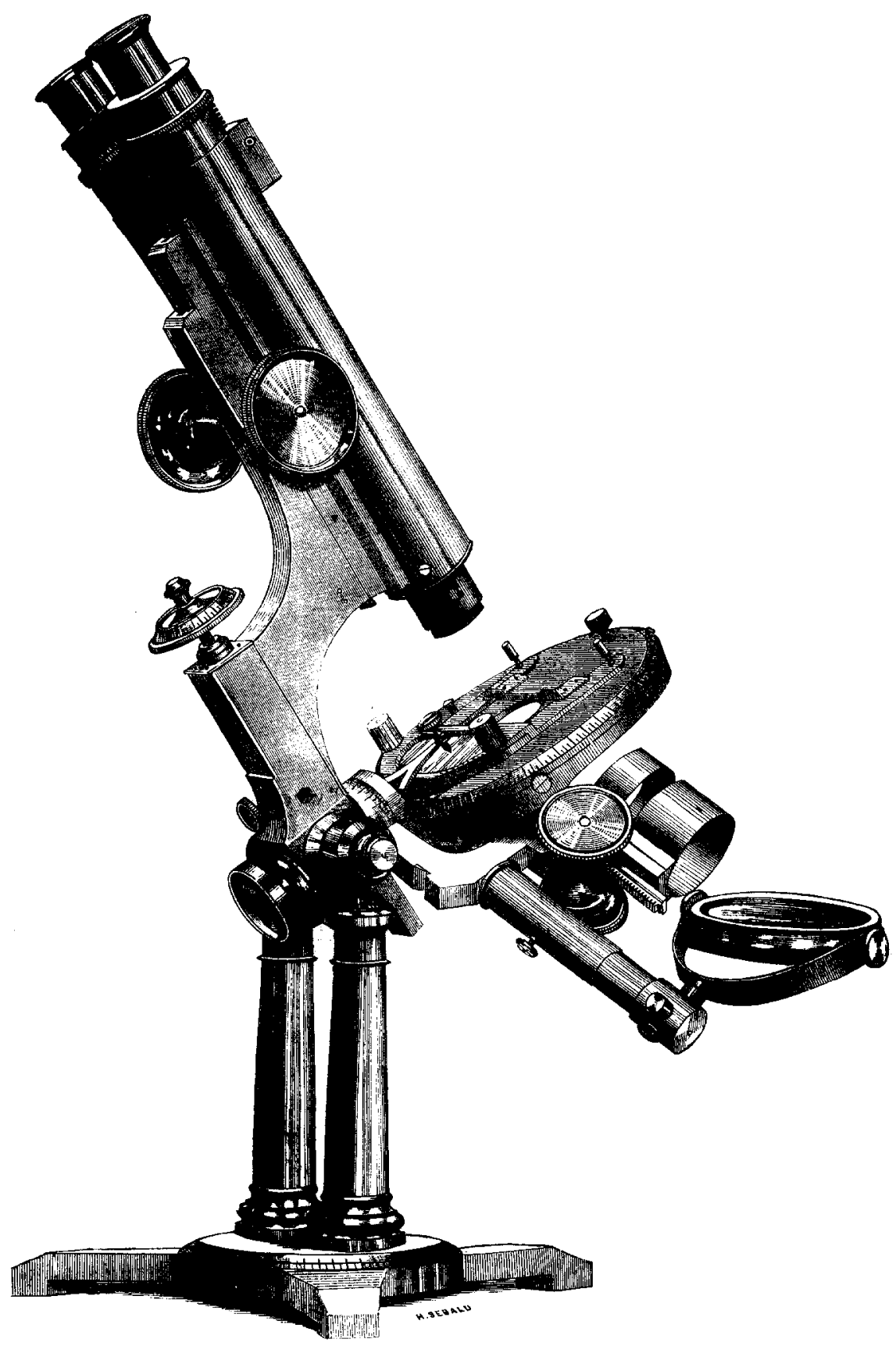

